\title{
INVESTIGATING MOBILE TRAFFIC VIOLATION TICKETING SERVICE IN EGYPT: THE PROVIDER AND USER PERSPECTIVES
}

\author{
Amer, H., Abd El Aziz, R. and Hamza, M \\ PQI, AASTMT, Janaklis, 661 Horreya Avenue, P.O. Box 1029, Alexandria, Egypt \\ Hanaa2m@yahoo.com \\ BIS Department, AASTMT, Jamal Abd El Nasser, Miami, P.O. Box 1029, Alexandria, Egypt \\ rasha a@aast.edu \\ GSB, AASTMT, Jamal Abd El Nasser, Miami, P.O. Box 1029, Alexandria, Egypt \\ meerh@aast.edu
}

\begin{abstract}
The advances in information and communication technology are affecting many aspects of the economy in developed and developing nations. The Internet and the World Wide Web innovations are increasingly promising to provide various tools to increase business and economic developmental processes for developing nations. Egypt in specific is one of the major countries in the region, especially with its very high population, around 94 million. This high population has in turn led to many challenges, on top of which is the transportation traffic, especially in the two main cities, Cairo and Alexandria.

The Information and Communication Technology development in Egypt, together with the very high mobile adoption rate, reaching over $116 \%$ subscribers in a country with such a high population brings a calling need to adopt a mobile application as a partial solution to the traffic problem in Egypt. However, adopting a new technology is not primarily a technical problem but is rather a social problem, where customers' acceptance plays an important role.

Accordingly, a structured questionnaire will be designed in English and Translated to Arabic. Then, questionnaires will be distributed over a sufficient number of Egyptian car drivers. Also Semi-structured face to face interviews were selected with decision makers. Both questionnaires and interviews inquire on how do both parties perceive the current traffic and ticketing system in Egypt, and what are the main factors that affect the driver intention to adopt an m-traffic in Egypt. Data collected will be analyzed. Finally, conclusions will be drawn and recommendations will be proposed.
\end{abstract}

\section{Indexing terms/Keywords}

Mobile usage; traffic violation; ticketing service; Egypt, user perspective; decision makers.

\section{Academic Discipline And Sub-Disciplines}

Business Information Systems and E-Business

\section{SUBJECT CLASSIFICATION}

Mobile traffic services

\section{TYPE (METHOD/APPROACH)}

Survey/Interview

\section{Council for Innovative Research}

Peer Review Research Publishing System

Journal: International Journal of Management \& Information Technology

Vol. 10 No. 1

editorsijmit@gmail.com

www.ijmit.com/ojs 


\section{INTRODUCTION}

Egypt is a major developing country in the region that has been particularly affected by the technological advances worldwide. This may be due to a very high population with around 94 million, $90 \%$ of which are concentrated on a small portion of the total land, especially in the two main cities, namely Cairo and Alexandria.

The transportation sector in particular, represents a major deterrent for trade and development in Egypt. This is clear, where million cars are driven through Cairo alone on a daily basis, and therefore, causing major congestions for a period that extends to over 15 hours a day, usually between 7 am and $10 \mathrm{pm}$ [1].

During the last 15 years, Egypt has directed an average portion of government investments towards the transportation and the information and communication technology sectors. The transportation sector has seen notable development. However, with such developments, transportation remains a problem despite the 1.8 billion dollars investment undertaken by the ministry of transportation to improve Cairo's chronic traffic problem [2].

The development of electronic traffic services via multiple electronic channels such as Internet and mobile technologies have made it possible to provide new kinds of added value for customers. Hence, developing a solution that provides people with accurate, timely and cost effective information regarding the status of traffic in Egypt through an integrated combination of both electronic and mobile commerce tools becomes a calling need, rather than just a trend to follow.

\section{PROBLEM DEFINITION}

The spread of traffic violations are accompanied by changes in service provision, control monitoring, fine ticketing, changes in customer behavior, and changing relations between citizens and police officers. Countries with high population and a great number of vehicles should normally have a greater capability to increase the economic growth of the society in general. However, if the vehicle traffic associated with the population is not well framed, it may cause congestions, frustration, pollution, and even low productivity levels.

This problem is amplified in Egypt, where daily traffic congestions usually extends to over 15 hours a day, making it very hard to reach their destination on time, and accordingly decreasing the overall efficiency and productivity of the individual driver. This highlights the fact that Egyptian drivers may be frustrated and would easily make traffic violations; especially if they are not satisfied with the current traffic ticketing system.

Although literature is rich with e-business solution, e-traffic solutions have been overlooked. This is clear where even studies that address e-traffic, seem to only consider it as a technical problem rather than a social one. Not to mention the clear gap in studying this area in the Egyptian context. Accordingly, and based on the previously presented reasons, investigating mobile traffic acceptance in Egypt becomes worthwhile and is thus, the aim of the current study.

\section{EGYPT ICT INDICATORS:}

Egypt ICT Strategy is a reflection of the ICT sector interest to adopt the democratic revolution witnessed by the Egyptian society by all its targets. According to ICT sector infrastructure indicators in 2013, the estimated of internet users increased to 37.14 million in 2013 compared to 31.52 million in 2012 representing an annual increase of 5.62 million users and annual growth rate of $17.83 \%$. Also internet penetration increased to $44.23 \%$ in 2013 compared to $38.26 \%$ in 2012 representing an annual growth rate of $5.97 \%$.

Proportion of internet broadband users is about $91.73 \%$ of total Internet users in 2013 compared to $90.23 \%$ of total internet users in 2012.Proportion of internet narrowband users is about $8.27 \%$ of total Internet users in 2013 compared to $9.77 \%$ of total internet users in 2012. The number of ICT companies increased to 5526 at the end of 2013, of which $77.3 \%$ were IT companies $15.1 \%$ Value added services and $7.55 \%$ communication companies. The number of ICT operating companies in 2013 was $12.25 \%$ higher than in 2012.

The number of fixed line and mobile subscriptions was 104.31 million in 2013, compared to 102.15 million in 2012 , with an annual increase of 2.16 million subscriptions and an annual growth rate of $2.11 \%$. Also the number of mobile subscriptions was 97.47 million in 2013, compared to93.68 million in 2012.This represents an annual increase of 3.79 million subscriptions and an annual growth rate of $4.04 \%$. Mobile subscriptions accounted for $93 \%$ of total telephone service subscriptions in 2013. Mobile penetration increased to $116.09 \%$ in2013, compared to $113.72 \%$ in 2012 , representing an annual growth rate of $2.36 \%$ [4]. On the other hand, fixed line penetration reached about $8.28 \%$ by the end of 2013 .

\section{MOBILE TICKTING}

Mobile ticketing is the process whereby customers can order, pay for, obtain and validate tickets from any location and at any time using mobile phones or other mobile handsets. Mobile ticketing could be defined as a method by which law enforcement agencies use in-car computers to create traffic citations in the field, and then print a hard copy for the offender[3]. Mobile ticketing has a number of perceived benefits, some of which are listed below:

- Reduced production and distribution costs associated with paper-based ticketing

- Reduced ticket printing and mailing cost

- Reduced paperwork time,

- Reduced chance of tickets being made void by human error 
- Immediate accessibility of citation information by other departments.

- Improved consumer convenience

- Increased revenue by increasing accessibility of tickets

- Reduced infrastructure costs

\section{TECHNOLOGY ADOPTION MODELS}

TAM is an adaptation of the Theory of Reasoned Action (TRA) to the field of Information Systems. TAM posits that perceived usefulness and perceived ease of use determine an individual's intention to use a system with intention to use serving as a mediator of actual system use. Perceived usefulness is also seen as being directly impacted by perceived ease of use. Researchers have simplified TAM by removing the attitude construct found in TRA from the current specification [5].

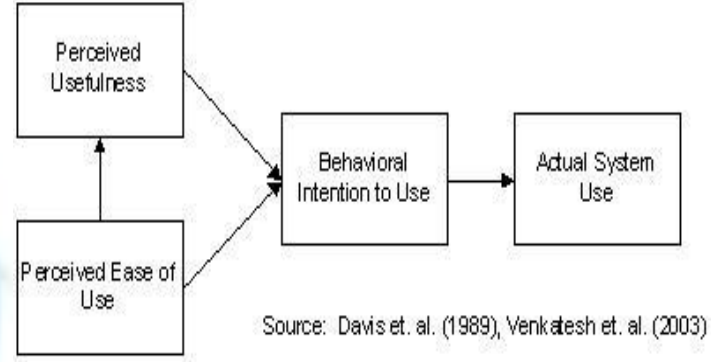

Figure 1: TAM model

The Theory of Planned Behavior suggests that human action is influenced by the attitude towards the behavior, subjective norm and perceived behavioral control. In combination, attitude, subjective norm and perceived behavioral control lead to the formation of a behavioral intention [6] [7].



Figure 2: Theory of Planned Behavior model

\section{TRAFFIC IN EGYPT}

Over the last few years, so many proposed solutions have been presented to solve traffic problems caused by the increasing population of Egypt. Stakeholders involved in different scenarios developed, included experts, traffic managers, supervisors, civil engineers amongst others. In June 2004, statistics showed that there were over 2.3 million cars that are driven through Cairo daily, including 1 million from other close provinces [1].

Therefore, causing major congestions for a period that extends to over 15 hours a day, usually between 7 am and $10 \mathrm{pm}$. Such congestions lead to major effects on business and local trading between Egypt's provinces.

During the last 15 years, Egypt has directed $17 \%$ of government investments towards the transportation and the information and communication technology sectors. Cairo underground introduced in 1987 serves more than 600 million passengers per year that is 60,000 passengers per hour in each direction. Moreover, the length of Cairo's road network has increased nearly threefold, from $15,000 \mathrm{~km}$ to $44,000 \mathrm{~km}$ since the mid-1980s [1].

Several major civil solutions were suggested and many were tested for implementation including the establishment of numerous tunnels, bridges, new exits to freeways.

However, with all such developments and despite the 1.8 billion dollars investment undertaken by the ministry of transportation to improve the capital's chronic traffic problem, transportation remains a problem. This could be mainly due to the fact that more than $90 \%$ of the population is concentrated on only $4 \%$ of the total land [2]. 


\section{MOBILE TRAFFIC IN EGYPT}

The developments in Egypt since 1985, with 3.6 million Internet users, 1.6 million personal computers installed, government-private sector partnership models and projects implemented including the PC for every home project, the free-Internet model project and the broadband initiative. The experience in Egypt has demonstrated the fact that with the proper infrastructure in place and a smooth and nation-wide awareness camping implemented that caters to cultural values, possible massive market penetration for different services could be successfully realized.

The service capitalizes on the innovations in information and communication technology and attempts to help people better utilize Cairo road network. The idea of this service can only be realized and well-diffused through the collaboration of potential partnering firms including private and public sector companies as well as government organizations, mainly transportation and traffic control departments, all contributing their strengths towards one competitive value chain.

Proposing such a solution was only to be realized if it was properly tested to be able to identify the challenges and opportunities as well as to adapt the details of its design and implementation to the norms and values of the local culture, because technologically adequate solutions and services may not fit particular settings for reasons that reflect organizational and national culture more than specific tasks [8].

\section{RESEARCH METHODOLOGY}

The current research uses the mixed methods approach where it involves mixing quantitative and qualitative approaches, and allows using different types of data in order to make comprehensive analysis. Both decision makers and car drivers are approached [9].

Based on the famous, most cited, and widely used technology adoption models, TAM and theory of planned behaviour will be used to determine whether the Ease of Use, Perceived Usefulness, compatibility and mobility are the main factors that affect drivers' intention to adopt mobile traffic violation ticketing service, and whether there are other important factors. These factors will be examined through designing and conducting both a semi-structured interview with a number of decision makers and a structured questionnaire to be distributed over Egyptian car drivers. Both the questionnaire and the interview questions will be designed and assembled based on reviewing literature.

Semi-structured face to face interviews were selected for the current study because they enable collecting hidden information; especially those related to feelings and attitude. In order to supplement the results of interview and to test the research hypotheses, a structured questionnaire will be conducted to save time and cost, and target a large amount of car driver respondents.

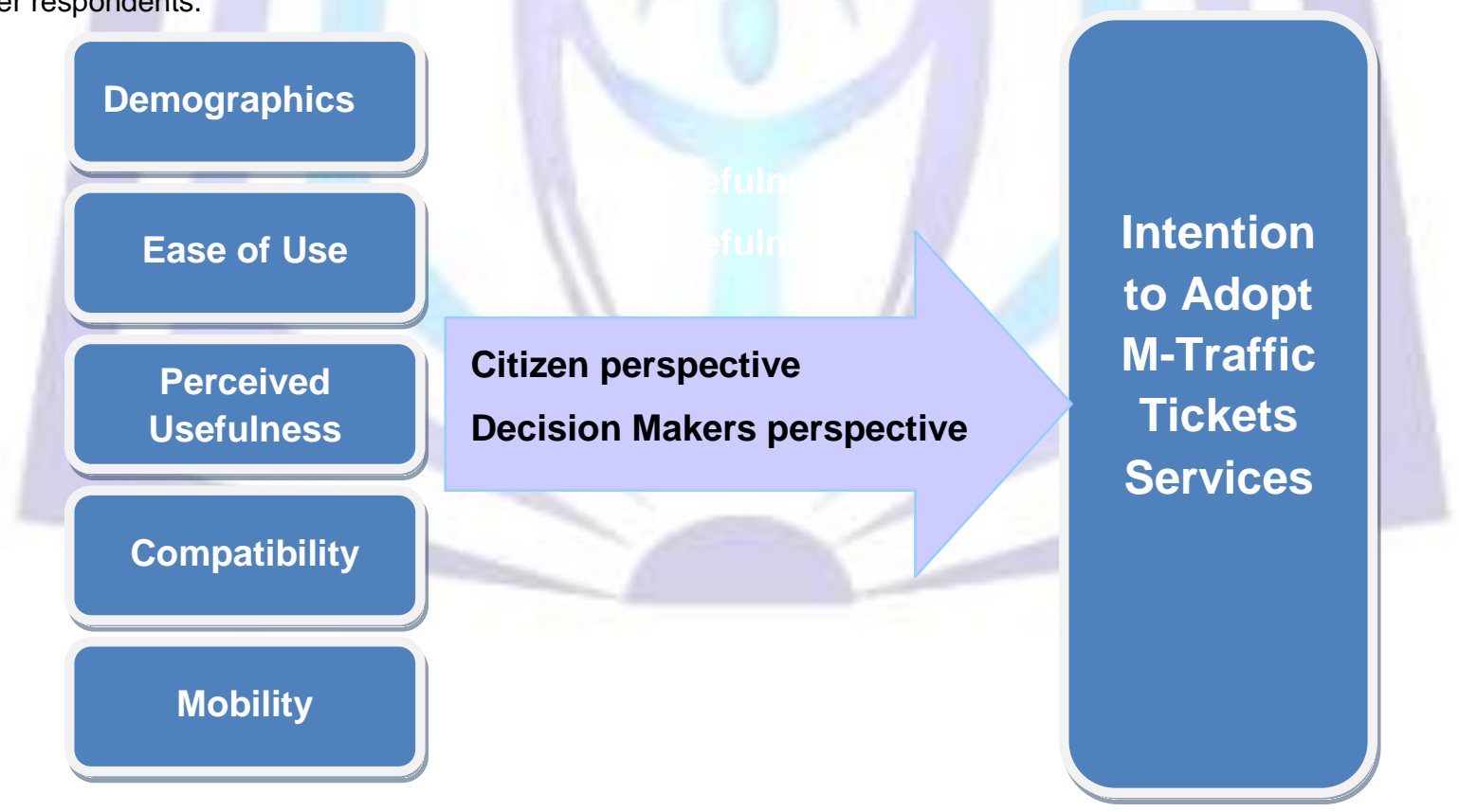

Fig 3: Research Framework

\section{RESEARCH HYPOTHESES}

Based on the great governmental advances in the last decade, and the government investments directed towards the transportation and the information and communication technology sectors [1], it was worth testing whether drivers are satisfied with the current Egyptian traffic system [10] and determine the main criteria that affect their intention to adopt the suggested mobile traffic ticketing system.

Accordingly, three hypotheses have been devised as shown in Table 1. 
Table 1. Research Hypotheses

\begin{tabular}{|l|l|}
\hline $\mathbf{H}_{\mathbf{0}} \mathbf{1}$ & Drivers are not satisfied with the current Egyptian traffic system. \\
\hline $\mathbf{H}_{\mathbf{0}} \mathbf{2}$ & There is no significant difference between ease of use and the intention to adopt $\mathrm{m}$-traffic ticketing service. \\
\hline $\mathbf{H}_{\mathbf{0}} \mathbf{3}$ & There is no relation between the perceived usefulness and the intention to adopt m-traffic ticketing service. \\
\hline $\mathbf{H}_{\mathbf{0}} \mathbf{4}$ & $\begin{array}{l}\text { There is no relation between the intentions to adopt m-traffic violation ticketing service with respect to } \\
\text { drivers' demographics }\end{array}$ \\
\hline $\mathbf{H}_{\mathbf{0}} \mathbf{5}$ & There is no relation between the compatibility and the intention to adopt m-traffic ticketing service. \\
\hline $\mathbf{H}_{\mathbf{0}} \mathbf{6}$ & There is no relation between the mobility and the intention to adopt m-traffic ticketing service. \\
\hline
\end{tabular}

\section{SAMPLING TECHNIQUES}

The population of interest for this questionnair is the Egyptian citizens with around 94 million, and specifically in Alexandria, which is the second-largest city and is the country's largest seaport in Egypt, in terms of importance and number of population. The sampling technique used will be stratified random sampling. Based on confidence level $95 \%$ and confidence interval \pm 5 , the sample size will be about 384 citizens [11].

The research interviews also targeted the second players whom are decision makers and police officers in Egyptian traffic ticketing and violation units in Alexandria. The research uses non probability sampling method, continence sampling method. This method is cheap, quick and also ensured picking respondents with a large variety of characteristics.

\section{QUESTIONNAIRE AND INTERVIEW DESIGN}

The questionnaire contained 28 questions arranged in 8 sections and a demographics section. The used scale in this study is between two to six-point Likert-scale'.

- Section 1: (Questions 1 to 3) asks about having Driver's License, its type and time for issuing it.

- Section 2: (Questions 4 and 5) asks about having an own car License and frequently of renewing it.

- Section 3: (Questions 6 and 7) asks about regularity of violate traffic rules and the types of your regular violations.

- Section 4: (Question 8) check drivers acceptance with the current traffic system.

- Section 5: (Questions 9 - 11) asks about frequently for using mobile technology to access the Internet, preferences and availability to get your traffic violation tickets via your mobile phone (intention to adopt $\mathrm{m}$-traffic tickets services).

Section 6: (Questions 12 - 14) check the perceived usefulness of m-traffic services.

Section 7: (Questions 15 - 17) check the compatibility of m-traffic services.

Section 8: (Questions 18 - 20) check the mobility of $m$-traffic services.

Section 9: (Questions 21 - 28) check intention to adopt m-traffic tickets services with respect to demographics (gender - marital status - age - annual income - level of education - occupation).

Also 10 open-ended interview questions were adopted and adapted from the literature review in order to understand the respondent's point of view rather than making generalizations about adopting Mobile Traffic Violation Ticketing Service.

\section{DATA ANALYSIS}

SPSS software was used for doing the statistical analysis for this study. The statistical analysis tests the reliability analysis, normality of distribution, the independent variable and the relation between the variables. In order to measure the reliability of the variables that affect mobile traffic violation ticketing service in this study, Reliability Analysis Cronbach's alpha was used. Kolmogorov-Smirnov and Shapiro-Wilk analysis was used to assess whether the data is normally distributed or not such as each distribution has different tests. The relation between the independent variable -the intention to adopt mobile traffic violation ticketing service- and the dependent variables; drivers satisfaction with the current traffic service, ease of use, perceived usefulness, compatibility, mobility with respect to driver demographics (gender - marital status - age - annual income - level of education - occupation) was measured by using Kruskal Wallis analysis $\mathrm{H}$ test. In addition to that Mann-Whitney $U$ test was used to analyse the relation between the variables and drivers' demographics.

\section{QUESTIONNAIRE FINDINGS}

This research focuses on the Egyptian driver's acceptance to the current traffic system then their intention to adopt mobile traffic violation ticketing service and the significant level with Ease of use, Perceived usefulness, Compatibility, and Mobility with respect to Egyptian drivers' demographics. 


\section{ISSN 2278-5612}

Questionnaire data collection and analysis reveals that the majority of respondents have valid driver's license, the type of the driving license for most of them is a private one and the rest have professional license.

Also a high percentage of the respondents have been issuing their driving license for more than five years, which shows that the majority of them have high driving experience. On the other hand, the minority of some of the respondents did not have their own car license.

Although, most of the respondents stated that they rarely violate the traffic rules, they had different opinions concerning the types of violations regularly committed by the respondents.

A high percentage of the respondents did not agree that traffic violations list fairly reflect the actual violations conducted by drivers as they see it unfair most of the times.

Regarding the respondents' access to the internet using mobile phones, it was found that the majority of them access the internet either daily or on a weekly basis.

More than the half of the respondents would like to receive their traffic violations list via mobile phones but the rest disliked the idea. As for the probability of using the mobile phones to receive traffic violations by the drivers, if this service is available, less than the half of them would like to use this service immediately.

Measuring drivers' acceptance, it was clear that Egyptian drivers are not satisfied with their traffic system. Also there is a significant difference between ease of use the new service and drivers' intention to adopt mobile traffic violation ticketing service.

In addition, a significant difference associated with the perceived usefulness with the drivers' intention to adopt mobile traffic violation ticketing service was revealed through the investigation.

\section{INTERVIEW FINDINGS}

From the data collection and data analysis of the interviews conducted with traffic directors in Egypt, it was clear that all the research dimensions, ease of use, perceived usefulness; compatibility and mobility have a relation with driver intention to adopt mobile traffic violation ticketing services.

The majority of directors are aware that the drivers are not satisfied with the current traffic system. They agree that the drivers are going to accept and use the new service, where real time mobile messages with traffic violation tickets are sent to drivers. They believe that this service will help improve the ticketing system.

Most of the directors agreed that if such service is available, there is going to be a high probability to adopt it by the Egyptian Interior Ministry. Another suggestion was to apply it by a specialized company as a kind of development for the traffic work. Each governor can provide this service in coordination-n with The Ministry. The service might be useful if it has a part of the offense.

The interviewees also agreed that this service will be greatly accepted by drivers regardless of their type of driving license. Not to mention that, it is a general request from all drivers. They stated that if mobile traffic violation ticketing service is already adopted, it would be easy to use for most of the drivers' especially who can deal with the mobile as general and internet in particular. Moreover, almost all of them believe that if this service is already adopted it will be useful for both parties, the ministry and drivers; because it will reduce the amount of irregularities.

It was also found from the interview analysis that interviewees think that if such service is adopted it will be suitable and compatible with drivers' life style especially if it is a free of charge service.

Finally all interviewees stated that if the service is already adopted, it will have a high mobility; because it would be time and place independent.

\section{SYNTHESISING FINDINGS}

The interpretations of both investigations (questionnaires and interviews) are almost similar in results. It is needed to find out whether and how these views and perspectives could be combined, what implications would such combination have on our final model, and whether the synthesis can be a basis of suggesting changes to practices in the Egyptian context.

Data collected from interviews showed an unanimity of police officers and decision makers that Egyptian drivers do not accept and are not satisfied with the current traffic system, where a theme was not hard to find, highlighted the fact that there is a match between the perspectives of the two main players in mobile traffic violation ticketing service, namely the decision makers and the drivers.

First of all, data collected from both of the questionnaires and interviews explained that the drivers are totally unsatisfied with the current traffic system. As a result, persuading them to use the new service will be easy.

Questionnaire findings confirmed that drivers have the intention to adopt the new service, which refers to sending real time traffic violation tickets to drivers on time as a mobile message. This is similar to interview findings which showed that the majority of traffic directors and decision makers in Egypt agreed that a large proportion of drivers are going to adopt the new service as it is a general request from most of them and it will be used depending on the type of the driver. Yet, it may still be difficult to adopt due to the lack of the traffic awareness among drivers. Also, although it may be great in theory, while practicing it, the culture of the Egyptian community might act as an obstacle in the application. 


\section{ISSN 2278-5612}

The interviewees believe that the ministry's perspective shows that adopting this service will help to improve the ticketing system in the Egyptian Interior Ministry in general and in particular, traffic departments by making contracts with specialized companies through traffic prosecutions (Egyptian Ministry of Justice) for many reasons as:

1. It is a way of developing all traffic departments.

2. It gives the driver an immediate notice of violation and an immediate deterrent.

3. It may lead to the discipline and commitment of the law, as the violator knows that the offense may have been detected.

4. It may reduce irregularities.

5. It may facilitate traffic violation ticketing service for drivers.

A significant relation was found between the new service ease of use, perceived usefulness, compatibility, mobility and drivers' perspectives with regards to their intention to adopt the mobile traffic violation ticketing service.

The decision makers' perspective reveals that if this service is already adopted, it will be easy to use for the drivers; especially for youths, private car owners, mobile phone frequent users, and those who want to abide by the rules and ethics of traffic. For those who cannot use the system, they can get help from the private offices.

The interviewees accept that if the service is already adopted, it will be useful for all parties, the Egyptian Interior Ministry, policemen, traffic administration and the drivers because it will reduce the amount of irregularities. They also think that if the new service is already adopted, it will be compatible with drivers' life style particularly if it is for free.

Finally, interviewees stated that adopting this service is going to be time and place independent for many reasons as:

1. It saves time and effort.

2. It guarantees access violation to the violator.

3. It prevents the replication.

4. It reduces frequency prosecution,

5. It enables nationwide irregularities to be paid through post offices or banks.

6. It allows immediate notification of violation and its values.

7. It is accessible; as mobile phones are always with drivers.

8. It may deter drivers from committing violations.

9. It encourages traffic discipline.

10. It enables avoiding crowds when receiving the irregularities certificate.

\section{CONCLUSION}

This study at hand provides results on mobile ticketing service acceptance in public transportation. The theoretical background for the study was adopted from an extensive review of literature, with special emphasis on technology adoption models in order to derive an adapted model that suits the mobile dominant environment in a developing context, where Egypt stands as an ideal example. The model was complemented with issues related to benefits of mobile technologies as well as mobile use situation.

The study results suggest the need for a tailored model that is simple and clear enough; due to the inadequacy of the general ones available in literature that leaves the Middle East with negligible attention.

From the above findings, we might be able to draw some tentative conclusions regarding the mobile traffic ticketing service that should be pursued in order to help decision makers understand and improve the current ticketing system. Clear and obvious dissatisfaction was reported with over $97 \%$ of respondents stating that the current ticketing system is unfair and does not reflect the actual violations that they conduct.

It was found that there are significant differences between Mobility, Usefulness, and Compatibility together with drivers' intention to adopt mobile traffic ticketing.

This clearly dictates decision makers to seriously support the adoption of a mobile ticketing system taking into consideration the four main success factors, Ease of ues, Mobility, Usefulness, and Compatibility.

Accordingly, decision makers should be able to communicate with drivers and license holders in order to promote the system by creating awareness and emphasizing the system's usefulness, mobility and compatibility with the Egyptian's life style.

Furthermore, while being beneficial for academics as well as management professionals, research main limitation where the study was conducted in Egypt should be taken into account. It is therefore difficult to generalize the results obtained to other type's contexts. 


\section{REFERENCES}

1. Abd El. Aziz, R., El Badrawy, R., and Ismail Hussien, M. (2014), 'ATM, Internet Banking and Mobile Banking Services in a Digital Environment: The Egyptian Banking Industry'. International Journal of Computer Applications, Vol. 90, No. 8, pp. 45-52, March 2014. Published by Foundation of Computer Science, New York, USA.

2. Altschuler A (2003) Mega-Cities: Innovations for Urban Life, Trinity College, www.megacitiesproject.org, [Accessed 27/09/2013].

3. Amer, H. and Abd El Aziz, R. (2012), "Mobile Traffic Violation Ticketing System in a Mobile Dominant Environment", ICT in Our Lives, How can Information and Communications technologies improve the life of Citizens?, Alexandria University, Alexandria, Egypt.

4. El Essawi, N. and Abd El Aziz, R. (2012), 'Determining the main Dimensions that affect E-Customer Relationship Management Readiness in the Egyptian Banking Industry', Int. J. Electronic Customer Relationship Management (IJECRM), Inderscience, Vol. 6 N3/N4, 2012

5. India, A (2008), 'Mobile Commerce Applications and Services, Mobile Marketing Association, electronic sources of information' [WWW]. Available from: http://www.cerebralbusiness.com/telecom/presentations/Venkat\%20lyer.pdf [Accessed 09/10/2013].

6. Venkatesh, V., Morris, M. G., Davis, G. B., and Davis, F. D. (2003). 'User acceptance of information technology: Toward a unified view'. MIS Quarterly, 27(3), 425-478.

7. Fishbein, M., \& Ajzen. I. (1975). Belief, attitude and behavior: An introduction to theory and research. Addison Wesley, Phillipines.

8. Abd El Aziz, R. (2012), ATM Usage: A Stakeholder Analysis in the Egyptian Context, 14 March 2012, LAP LAMBE RT Academic Publishing, ISBN-10: 384840835X, ISBN-13: 978-3848408351.

9. Markus M.L. (2004) 'Techno Management: Using IT to Drive Organizational Change', Journal of Information Technology, 19, 3-19 [Accessed 10/10/2013]

10. Petrella, M and Lappin, J. (2006)." Driver Satisfaction With an Urban Arterial After Installation of an Adaptive Signal System" electronic sources of information'.

11. Sekaran, U. (2003). "Research methods for business:Skill building approach", JhonWiley\&Sons,Inc. ISBN10: 0471203661 | ISBN-13: 978-0471203667 | Edition: 4

\section{Authors' biography}

Hanaa Amer is a DBA candidate at the Graduate School of Business, the Arab Academy for Science and Technology, Alexandria, Egypt. She has been awarded her Master of Business Administration, AASTMT. She has published in the ECommerce field.

Rasha Abd EI Aziz is currently the Head of Business Information Systems, and Associate Professor at the College of Manaement and Technology, the Arab Academy for Science and Technology, Egypt. She is a SAP Certified Business Associate. She has been awarded her PhD in 2009, the University of the West of England, Bristol, UK. She was awarded her MBA in 2002, AASTMT. She has published a book, and has published extensively in academic journals and International conferences. She has successfully supervised and is currently supervising a number of PhD and Master Theses both in UK and Egypt. 